\title{
Marketing da informação: abordagem inovadora para entender o mercado e o negócio da informação
}

\author{
Sueli Angélica do Amaral \\ Doutora em ciência da informação pela Universidade de Brasília. \\ Brasília-DF. Professora associada da UnB, cedida ao Instituto \\ Brasileiro de Informação em Ciência e Tecnologia (Ibict), \\ Coordenação de Ensino e Pesquisas - Rio de Janeiro, RJ - Brasil \\ E-mail:samaral@unb.br
}

\section{Resumo}

Mostra o marketing da informação como abordagem inovadora da gestão da informação e do conhecimento em unidades de informação, a partir do entendimento do mercado e do negócio da informação na área em que atuam suas organizações mantenedoras, estejam elas inseridas no setor com fins de lucro ou não. Destaca que, diante dos novos temas e da mudança de paradigmas, o marketing da informação reflete tanto a natureza mutável dos serviços de informação como as perspectivas teóricas e práticas do marketing, principalmente após o surgimento da Internet e da Web. Conclui que é importante estudar, pesquisar e desenvolver estudos sobre marketing na ciência da informação para evidenciar os benefícios da apropriação conceitual do marketing nesta área do conhecimento e dar visibilidade ao papel desempenhado pelas unidades e profissionais da informação como agentes sociais capazes de contribuir para o desenvolvimento da sociedade.

\section{Palavras-chave}

Marketing da informação. Unidade de informação. Mercado da informação. Negócio da informação. Oferta de informação. Demanda de informação.

\section{Information marketing: an innovative approach to understand information market and business}

\begin{abstract}
The objective of this paper is to present marketing information as an innovative approach referring to information and knowledge management in information units by understand the information market and business in the area of the maintaining organization performance either in profit or non-profit sectors. On account of the new themes and change of paradigms, information marketing reflects both the unstable nature of information services and the theoretical and practical perspective of
\end{abstract}

marketing, mainly after Internet and web came up. The conclusion is that it is important to analyze, research and develop studies about marketing in the area of Information Science in order to bring forth the benefits of precise terms concerning marketing in this area of knowledge and to underline the role performed by the units and professionals of information as social agents for contributing to the development of society.

\section{Keywords}

Information marketing. Information unit. Information market. Information business. Information offer. Information supply.

\section{INTRODUÇÃO}

Este artigo tem como objetivo mostrar o marketing da informação como abordagem inovadora da gestão da informação e do conhecimento em unidades de informação, a partir do entendimento do mercado e do negócio da informação na área em que atuam suas organizações mantenedoras, estejam elas inseridas no setor com fins de lucro ou não. Neste sentido, alguns esclarecimentos conceituais tornam-se necessários e se apresentam nesta introdução.

O termo unidade de informação, embora bastante difundido na literatura, ainda não é consensualmente definido. Guinchat e Menou (1994, p.337) usam o termo para se referir aos setores das empresas que têm como missão: "identificar, com a maior precisão possível, as informações que podem ser úteis aos usuários, ajudá-los a recuperar os documentos primários correspondentes e responder às suas perguntas". Tal definição não deixa claro se as bibliotecas também poderiam ser consideradas unidades de informação. Esta dúvida não persiste na descrição de Amaral (1998, p.15), que defende as unidades de informação como: 
[...] todo tipo de organização atuante na área de informação e/ou documentação, que trabalhe com os registros do conhecimento em todo e qualquer tipo de suporte, independentemente de sua designação. São consideradas unidades de informação, todos os tipos de bibliotecas, mapotecas, centro/ serviço/departamento/sistema de informação e/ou documentação, de acordo com a sua área de atuação e extensão.

Segundo Sampaio (2009, p.17), alguns autores se referem à unidade de informação como termo genérico para denominar diferentes tipos de bibliotecas. Na concepção da autora, o uso se justifica "na medida em que as bibliotecas aumentaram seu escopo de atuação no que tange à gestão de informações armazenadas não somente em suportes físicos (livros/papel), mas também em suportes eletrônicos, digitais e virtuais".

Muitos estudiosos acreditam que o termo biblioteca não mais corresponde à realidade da sociedade contemporânea.

Ao relatar sua preocupação com o futuro das bibliotecas, Cunha (2000) indaga sobre o relacionamento entre as bibliotecas tradicionais e digitais. Reflete sobre o assunto fundamentado em Michael Dertouzos, que afirma:

As bibliotecas continuarão com a custódia dos materiais educativos sólidos, com destaque para os livros. Contudo, elas se tornarão também gerenciadoras de linhas de comunicação com outros locais de conhecimento, com a condição de que as bibliotecas físicas controlem a qualidade das bibliotecas virtuais, decidindo quais conhecimentos existentes em outras instituições merecem menção pelos selecionadores e hiperorganizadores da biblioteca local. (...) O gerenciamento eficaz desses selecionadores de conhecimento será crucial para a qualidade das instituições de ensino no futuro. (DERTOUZOS, 1997, p. 241).

Desse modo, aceito ou não, o uso do termo biblioteca prevalecerá por algum tempo, quando se pensa em uma organização prestadora de serviços de informação. Seja tradicional, híbrida ou digital, a biblioteca precisa ser vista como uma organização submetida a todos os fatores de impacto do ambiente em que se insere, e sua atuação é determinada pela organização mantenedora a que está vinculada.

Diante dos comentários apresentados, os termos biblioteca e unidade de informação serão utilizados como sinônimos neste artigo.

\section{DESAFIOS DAEVOLUÇÃO DA SOCIEDADE}

Todas as organizações, inclusive as unidades de informação, estão inseridas no contexto da sociedade, seja qual for o modelo que a denomine: sociedade pós-industrial (BELL, 1977), sociedade pós-moderna (LYOTARD, 1990), sociedade póscapitalista (DRUCKER, 1994), sociedade em rede (CASTELLS, 1999), sociedade da informação (MATTELART, 2002). Entretanto, observa-se que ocorre uma transformação, provocando a mudança de enfoque em relação ao fator de produção e ao fator de desenvolvimento econômico da sociedade. A base dessa transformação é que o setor de informação é intensivo em conhecimento e não em mão de obra. Nessa mudança, o valor agregado do conhecimento ou do segmento tecnológico é progressivamente mais importante, quando incorporado ao bem, provocando a transformação industrial da matéria-prima informação pelo seu valor agregado (BOTELHO; AMARAL; BAPTISTA, 1994).

Castells (1999, v.1, p.174-176) é de opinião que a economia informacional caracteriza-se pelo desenvolvimento de uma nova lógica organizacional, que está relacionada com o processo atual de transformação tecnológica, mas não depende dele. Defende que a convergência e a interação entre um novo paradigma tecnológico e uma nova lógica organizacional constituem o fundamento histórico da economia informacional. Ao explicar os pontos fundamentais de sua análise sobre as trajetórias organizacionais, destaca que o objetivo principal das 
transformações organizacionais em várias formas é lidar com a incerteza causada pelo ritmo veloz das mudanças no ambiente econômico, institucional e tecnológico da empresa, aumentando a flexibilidade em produção, gerenciamento e marketing. Considera que a mais abrangente tendência de evolução das organizaçõees é a transição da produção em massa para a produção flexível, que surgiu como possibilidade de adaptar a produção à transformação contínua sem pretender controlá-la em um padrão de arte industrial ou produção personalizada.

Segundo Rowley (2002), no ambiente digital, onde operam bibliotecas digitais, comércio eletrônico e negócios eletrônicos (e-business), a informação digital tornou-se cada vez mais importante, passando a desempenhar duplo papel nos processos de marketing.

Um significativo componente da atividade do comércio eletrônico e das e-empresas relaciona o marketing com a entrega de produtos de informação. Exemplos destes produtos de informação são jornais e revistas eletrônicos, newsletters, e-books, música digital, áudio e vídeo, software, imagens. Além disso, no mundo digital e eletrônico, os prestadores de serviços também usam a informação como substitutivo do contato humano. Catálogos de produtos, ofertas especiais, listas de FAQ (Frequently Asked Questions), sessões de ajuda são exemplos óbvios do uso da informação na promoção de serviços e no apoio ao relacionamento com os clientes. Juntos, esses usos justificam a importância da informação no ambiente digital (ROWLEY, 2002).

Rowley (2006, p.3) destaca o marketing para as organizações que oferecem produtos e serviços de informação da informação como um processo pelo qual as necessidades de informação e de conhecimento dos usuários são atendidas por meio de adequada troca pelos recursos de informação e serviços dessas organizações. Isto envolve:

a) pesquisar e entender as necessidades dos usuários e outros fatores do mercado; b) selecionar e definir os usuários ou grupos de clientes que os serviços de informação atenderá;

c) definir a oferta, em termos de produtos e elementos associados do maketing mix e fazer isso como referência para o valor potencial que a oferta pode proporcionar ao usuário;

d) oferecer produtos e serviços alinhados às expectativas e interesses dos usuários;

e) assegurar a comunicação e o engajamento com a comunidade usuária;

f) estabelecer o direcionamento estratégico e fazer planos para dar suporte e continuidade ao engajamento com a comunidade usuária.

Para Amaral (2004, p.59-60), o escopo de atuação para o estudo do marketing da informação referese às organizações e aos sistemas envolvidos com os processos de gestão da informação relativos às diversas etapas do ciclo da informação, como a coleta, o tratamento, a disseminação e o uso da informação. Essas organizações e sistemas, comprometidos com a oferta de produtos e prestação de serviços de informação, são considerados unidades de informação por se tratarem de organizações e sistemas que integram suas organizações mantenedoras e não existem de forma independente do seu órgão mantenedor. Estes, por sua vez, podem ser do setor com fins de lucro ou não. Como exemplo, pode-se considerar a mapoteca de uma empresa privada (setor com fins de lucro) e a biblioteca de uma universidade pública (setor sem fins de lucro).

Ao destacar no título de seu livro o Marketing da Informação (em inglês, Information Marketing), Rowley (2006, p.xiii) o define como "o marketing dos produtos e serviços que têm a informação como base."

Percebe-se que, para ressaltar a importância da informação, o marketing é mencionado no enfoque relativo à economia da informação, no sentido do entendimento do valor da informação. Entretanto, 
há pouco tempo, o marketing de massa fazia sucesso. Agora, precisa ser direto e pessoal, pois o mundo digital pressupõe interatividade, característica fundamental à mudança de paradigma no marketing. O internauta visita o website que quer, na ordem que bem entender e na hora em que ele quiser. Assim, a tecnologia está propiciando que o usuário interaja com a informação disponível. Isto pode resultar na mudança das leis que regem as atividades de marketing.

$\mathrm{Na}$ prática, esta tendência pode ser vista como vantagem para o fornecimento de produtos e serviços de informação personalizados, que são cada vez mais exigidos pelos indivíduos e organizações, que também vão se tornando mais e mais exigentes no exercício de seus direitos e cidadania.

Para isso, o contexto evolutivo do enfoque da informação e a visão do novo paradigma, preconizando e dando prioridade ao acesso à informação, precisam ser considerados, quando se pensa no desempenho efetivo das bibliotecas e demais unidades de informação diante dos desafios impostos pela sociedade.

A informação precisa ser estudada como o fator essencial que permitirá o 'salto' na verdadeira transformação da sociedade. Isto porque seu valor econômico parte do pressuposto de que informação gera conhecimento e esse, quando acumulado, possibilita a produção científica e tecnológica e é responsável pela geração de bens e serviços.

Moody e Walsh (1999) apresentaram, durante a Conferência Europeia de Sistemas de Informação de 1999, um estudo sobre a mensuração do valor da informação, avaliando-a como um bem ou ativo.

$\mathrm{Na}$ caracterização da informação como ativo intangível, Moody e Walsh (1999) buscaram fundamentos em Godfrey et al. (1997) e Henderson e Peirson (1998), ao entenderem que esse é um bem não físico ou ativo intangível, porque representa um serviço potencial e pode trazer benefícios econômicos no futuro, de acordo com o seu controle pela organização que detém o ativo para facilitar o acesso à informação e pelos resultados obtidos em transações passadas. Logo, embora não tenha a forma física de um objeto, a informação possui relevância quando existe e é acessada.

Moody e Walsh (1999) também admitiram que a informação não obedece às leis econômicas como os outros tipos de bens, porque suas propriedades são únicas. Por essa razão, definiram as sete leis para melhor entendimento desse ativo intangível de modo a tornar possível a mensuração do seu valor. São elas:

a) a informação é infinitamente compartilhável;

b) o valor da informação aumenta com o uso;

c) a informação é perecível;

d) o valor da informação aumenta com a acurácia;

e) o valor da informação aumenta quando combinada com outra informação;

f) mais informação não é necessariamente melhor; g) a informação não se esgota com o consumo.

Ao analisar as leis da informação apresentadas, percebe-se que existe inter-relacionamento entre elas. A primeira (compartilhamento infinito) e a última (consumo) são determinantes para o entendimento de que, se a informação pode ser compartilhada sem se esgotar, o acesso a ela deve ser permitido, sem prejuízo para a organização que a detém. Neste caso específico, é preciso resguardar o acesso às informações internas da organização consideradas estratégicas ou concorrenciais. Além disso, o uso da Internet para acessar informação vem confirmar essas leis.

A efetividade da segunda lei (valor/uso) está na compreensão de que, na oferta da informação, o provedor precisa se preocupar com o uso da informação oferecida, que por sua vez só será utilizada se atender à demanda. Isto significa que 
para os potenciais usuários do serviço de informação oferecido o utilizem, é preciso que saibam que a informação está disponível, onde podem encontrála, como podem ter acesso a ela e como poderão usá-la. Esta lei reflete a responsabilidade social de quem oferece informação e, portanto, deve exercer o papel de agente social responsável pela educação relativa às competências em informação. Nesse sentido, a postura do profissional que presta serviços de informação deve ser orientada pelo entendimento dessa responsabilidade social em cada instituição em que o serviço de informação oferecido se insere.

A terceira lei (perecibilidade) fundamenta-se nos princípios da obsolescência da informação, que pode variar de acordo com o tipo de informação e área do conhecimento a que se refere. A informação mercadológica, por exemplo, pode ser válida por curto tempo, pois as mudanças são constantes e muitas delas imprevisíveis, tornando a informação perecível. No caso de uma informação histórica, sua validade permanece através do tempo quando se trata do relato de fato histórico decorrido. Ainda que outro fato seja descoberto, desmentindo o fato histórico anterior, ele continuará válido para a compreensão da própria história a que se refere. Isto deve ser considerado quando se deseja determinar o valor da informação.

Quanto à acurácia da informação, lembrada na quarta lei (valor/acurácia), De Sordi (2008, p.6264) lembra de sua importância na identificação da veracidade e na confiabilidade da informação pelo usuário. Por parte da pessoa ou organização que presta serviços de informação, é preciso que a informação disponível não seja imprecisa, vaga, probabilística, inconsistente, incompleta, ou incerta. Portanto, a acurácia da informação é um atributo que aumenta o seu valor.

Também é importante saber que, de modo geral, quando se compara ou combina uma informação à outra, seu valor se amplia, como define a quinta lei (valor/combinação). Para os tomadores de decisão, responsáveis pelos serviços de informação prestados, por exemplo, a integração das informações originárias de diversos sistemas que armazenam dados sobre perfis de usuários ou consumidores e seus comportamentos de uso da informação disponível pode fornecer informações combinadas e consolidadas. Certamente, essas informações terão maior utilidade para as decisões relativas aos esforços referentes a futuras campanhas promocionais de um produto ou serviço de informação a ser oferecido. Por consequência, atendidos esses princípios, os usuários e consumidores podem ser beneficiados com a oferta de informação mais adequada aos seus interesses.

No entanto, a sexta lei (excesso) leva a refletir que o excesso de informação muitas vezes significa desinformação. Nas organizações podem existir vários sistemas de informação, mas nem sempre a recuperação das informações armazenadas é realizada a contento. $\mathrm{Na}$ maioria das vezes há dificuldades a serem enfrentadas no processamento desse material, quando a tecnologia é empregada em detrimento das possíveis funcionalidades dos sistemas implantados em benefício dos seus usuários.

As leis da informação definidas por Moody e Walsh (1999) fundamentam a proposta dos autores para mensurar o valor da informação. Para eles, o entendimento sob o ponto de vista da economia da informação é essencial para sua gestão. Apesar de não se reportarem ao acesso à informação na Internet e na web, esses fundamentos ainda não se tornaram obsoletos.

Para complementar essa abordagem, recorre-se a Forrester Research, Inc. (2008), quando relata que as pessoas entendem que existem dois lugares onde a informação existe: em algum lugar da sua organização, ou para consumo na web. Segundo o relatório apresentado, as pessoas esquecem que muitos fatos e pesquisas precisam de um acordo ou assinatura para se ter acesso a eles, e que as bibliotecas das organizações, por meio desses acordos e assinaturas, tornam-se cada vez mais 
virtuais para propiciar e ampliar as condições de acesso à informação. Entretanto, ressaltam que as bibliotecas não divulgam seu esforço no desempenho dessas funções, ao atuarem como centros de capacitação de conhecimento e assumirem suas responsabilidades como capacitadoras e catalisadoras do conhecimento.

Assim, compreender essa abordagem facilita o entendimento e a aceitação de que as organizações prestadoras de serviços de informação devem ser consideradas como empresas inseridas no negócio da informação. A concepção da biblioteca ou unidade de informação como empresa também é importante para entender a visão que ela possui e como se estrutura para dirigir e desempenhar suas atividades, em alinhamento com a área do negócio em que atua sua organização mantenedora.

Portanto, seja qual for a unidade de informação considerada, guardando-se suas específicas peculiaridades, essa biblioteca, enquanto organização, precisa conhecer seus competidores e o meio ambiente em que se insere. Se agir dessa maneira, poderá com maior facilidade selecionar as oportunidades para agir e se antecipar ao oferecer as informações do interesse de seus usuários. Consequentemente, terá melhores condições para alcançar resultados positivos, ao satisfazer a contento as necessidades de informação desses usuários e fazer melhor uso dos recursos disponíveis.

Os prestadores de serviços de informação devem prestar atendimento de modo a atender a demanda dos seus usuários e para isso, precisam identificar e entender os requisitos de exigência desses novos consumidores.

Nesse sentido, as unidades de informação poderão ser bem-sucedidas na gestão da informação orientada para o mercado, uma vez que são responsáveis pela oferta de informação tanto no ambiente tradicional quanto no ambiente web no contexto do mercado da informação em que se inserem.

\section{Mercado da informação: o cenário de negócio da informação}

Antes de abordar o mercado da informação, deve-se entender o que é mercado.

Em 1978, Kotler (1978, p.37-38) definiu mercado como "um grupo distinto de pessoas e/ou organizações que têm recursos que querem trocar, ou que poderão, concebivelmente, trocar por benefícios distintos". Ele complementa que, do ponto de vista da organização, mercado "é uma arena em potencial para a troca de recursos".

Mais tarde, em 2000, Kotler (2000, p.140) apresentou a definição de mercado como "o conjunto de todos os compradores, efetivos e potenciais, de uma oferta ao mercado”. A nova definição parece não agregar valor àquela apresentada em 1978, até porque, o autor usa a própria palavra mercado na definição do termo em questão. $\mathrm{Na}$ mesma obra, Kotler afirma que "o tamanho de um mercado depende do número de compradores que possa existir para uma determinada oferta ao mercado".

Para detalhar essa temática, Kotler (2000, p.140) definiu mercado potencial como "o conjunto de consumidores que possuem renda, interesse suficiente por uma oferta ao mercado" e acrescenta que o "mercado disponível é o conjunto de consumidores que possuem renda, interesse, acesso e uma determinada oferta". Permanece então, a ideia de que o mercado engloba tudo: o cenário, os atores e os processos de determinado setor.

No entendimento de Kotler (2000, p.31), na economia moderna são considerados cinco mercados básicos:

Fabricantes (mercados produtores) se dirigem a mercados de recursos (mercados de matériasprimas, de mão-de-obra, de recursos financeiros), compram recursos e os transformam em mercadorias e serviços. Então eles vendem os produtos acabados a mercados intermediários, que os vendem aos mercados consumidores finais. Os consumidores vendem sua capacidade de trabalho e recebem dinheiro, com o qual pagam por bens e serviços. 
O governo (mercados governamentais) arrecada impostos para adquirir bens dos mercados de recursos, produtores e intermediários e utiliza esses bens e serviços para oferecer serviços públicos. A economia de cada país, assim como a economia global, consiste em complexos conjuntos de mercados que interagem, ligados por processos de troca.

No que diz respeito ao mercado da informação, sua natureza está em evolução contínua e todas as organizações da indústria da informação precisam formar novas alianças estratégicas, identificar novos segmentos de mercado, desenvolver novos produtos e novos relacionamentos com seus públicos, empregando vasto arsenal de estratégias, táticas, técnicas e instrumentos de marketing para obter sucesso no ambiente de mudança de paradigmas na sociedade (ROWLEY, 2006, p.xiii).

É notório o impacto da globalização, da digitalização, da conectividade, da personalização, da velocidade, dos relacionamentos com os clientes, dos serviços de autoatendimento, da comunicação de marketing, dos novos sistemas de gestão, do atendimento ao cliente, principalmente depois do surgimento da internet. Existe uma série de novos temas e uma mudança de paradigma que reflete tanto a natureza mutável dos serviços de informação quanto as perspectivas teóricas e práticas do marketing.

Além disso, no mercado da informação, pode-se perceber, como mostra Robredo (2003, p. 9), que a informação é suscetível de ser:

- registrada (codificada) de diversas formas;

- duplicada e reproduzida ad infinitum;

- transmitida por diversos meios;

- conservada e armazenada em suportes diversos;

- medida e quantificada;

- adicionada a outras informações;

- organizada, processada e reorganizada segundo diversos critérios;

- recuperada quando necessário segundo regras preestabelecidas.
No Brasil, na área de ciência da informação são poucos os autores que discutiram sobre o mercado da informação. Ao descrever o mercado da informação brasileiro, Valentim (2000) afirma que:

entre o discurso político-econômico e a prática político-econômica brasileira verifica-se um enorme fosso, de difícil transposição. O fosso, nesse caso, é representado pela falta de políticas claras e disseminadas, pela falta de recursos financeiros, pela falta de entendimento da importância da informação nesse processo e, talvez o mais representativo, o conservadorismo da iniciativa privada nesta área.

Na opinião de Valentim (2000), por questões socioeconômicas, a demanda do mercado da informação brasileiro existe, mas está "totalmente reprimida”. Com base em Wurman (1995, p.47-48), ela entende esse mercado da seguinte forma:

a) mercado de informação cultural - abrangendo as áreas de artes, humanas e sociais;

b) mercado de informação de mídias - abrangendo as áreas de comunicação e da ciência da informação;

c) mercado de informação em ciência e tecnologia - abrangendo as duas áreas mencionadas, em toda a sua amplitude e,

d) mercado de informação de referência - abrangendo todas as áreas do conhecimento humano, apresentado de forma referencial, de apoio ou cadastral.

Valentim (2000) observa que os cinco mercados de informação se abastecem da "produção de informação nas diferentes áreas do conhecimento a que estão ligados, estabelecendo um ciclo vivo ou uma cadeia viva, que crescerá sempre que se alimentar das informações produzidas." Ela entende que a

cadeia produtiva de informação passa pela própria produção de informação, gerada nas diferentes áreas a que está ligada, consolidando desse modo, as informações geradas através de bancos de dados que realmente sejam disponibilizados democraticamente aos diversos segmentos da sociedade. 
A pesquisa de Mostafa e Pacheco (1995) sobre o mercado de informação brasileiro buscava ampliar o campo de atuação profissional do bibliotecário "para ocupar postos informacionais fora das bibliotecas." Em artigo sobre o mercado emergente de informação, as pesquisadoras tinham como objetivo "identificar os balcões de informação não convencionais", considerados por elas como um tipo de segmento não imaginado pelo bibliotecário como mercado de trabalho. As autoras apresentaram um estudo limitado "ao setor terciário, sendo as atividades de comércio e serviços vistas como o último dos balcões, aqueles que dão para a sociedade, intermediando a relação com os outros setores. O balcão de serviços é o do como fazer, é o balcão da tecnologia, da terceirização." (MOSTAFA; PACHECO, 1995)

Ao estudar o mercado da informação no Brasil, Barreto (1996; 1999; 2000) assegura que:

em um mercado tradicional, oferta e demanda se ajustam, considerando as condições próprias deste mercado. Se não considerarmos os radicalismos do mercado, a demanda tem um papel primordial no ajuste. Se a demanda por determinado produto aumenta ou diminui, a oferta tende a se ajustar a essas variações.

Quando menciona 'mercado tradicional', apesar de não definir claramente o mercado a que se refere, Barreto $(1996,1999,2004)$ parece aceitar, implicitamente, o princípio básico de marketing relacionado aos estudos de ajustes entre oferta e demanda do mercado, denominado por ele tradicional. Porém, ao manifestar sua opinião relativa à oferta e demanda da informação, Barreto (1996; 1999; 2000) não aceita a transposição conceitual dos estudos de marketing ao mercado da informação, por entender que "o mercado de informações tem características que lhe são peculiares". Para ele, "estudos já realizados permitem indicar que na ambiência de informação é a oferta que determina a demanda por informação."

Ao expressar sua opinião sobre a aplicação das técnicas de marketing ao mercado da informação,
Barreto (1996;1999;2000) deixa claro, acertadamente, o fato indiscutível de que o mercado da informação tem suas características peculiares. Portanto, não seria possível aceitar a ótica de marketing aplicada à informação sem levar em conta tais especificidades. Entretanto, para mencionar apenas um exemplo, esses aspectos foram considerados por Moody e Walsh (1999), quando fundamentaram seus estudos sobre o valor da informação. Logo, estudos que consideram a informação e o seu valor existem, ainda que não sejam muito frequentes.

Todavia, a afirmativa de Barreto (1996; 1999; 2000) de que "na ambiência de informação é a oferta que determina a demanda por informação", deve ser considerada como significativo alerta aos profissionais que atuam em unidades de informação. Ao manifestar sua opinião, o autor parece não acreditar que esses profissionais possam estar preocupados em entender a demanda a ser atendida e que não planejam a oferta de produtos e serviços de modo a satisfazer tal demanda. O alerta implícito na opinião do autor retrata que as atividades desenvolvidas pelos profissionais nas unidades de informação parecem não evidenciar à sociedade o papel social dessas organizações.

Contudo, tendo como base as definições de mercado apresentadas por Kotler (1998; 2000), a análise das leis da informação propostas por Moody e Walsh (1999) e a visão de Rowley (2006) sobre marketing da informação, entende-se que o mercado da informação consiste naqueles que possuem interesse real ou potencial na própria informação. Assim, este mercado é composto por todas as pessoas e organizações que, além de terem concebível interesse pela informação, também devem ter os recursos certos e necessários para serem trocados por ela. Portanto, nesse mercado, o interesse pela informação deve estar presente tanto naqueles que oferecem informação (oferta) como naqueles que precisam e a buscam (demanda).

A partir desse raciocínio, no mercado em análise, os profissionais das unidades de informação 
que ofertam produtos e serviços informacionais também precisam estar aptos para entender o tipo de demanda a ser atendida, se não quiserem correr o risco de ter sua oferta limitada a estoques informacionais não procurados e sem utilização, seja qual for a justificativa alegada para tal situação.

O processo de ajustes da oferta à demanda de informação leva a refletir sobre as possíveis vantagens do marketing como ferramenta gerencial para melhorar o desempenho das unidades de informação, organizações de valor essencial para o desenvolvimento social, econômico, político e cultural da sociedade.

Neste contexto, principalmente após o surgimento da internet, cresceram os ambientes de informação digital, como as bibliotecas digitais e virtuais e os negócios (e-business e e-commerce), que passaram a lidar com a informação digital.
Porém, é preciso refletir que a matéria-prima do trabalho cotidiano, a informação e o conhecimento são por natureza complexos, mutáveis e diversificados. Tal complexidade pode explicar a falta de consenso como resultado dos estudos epistemológicos sobre o conceito e definição de informação e conhecimento. Como consequência, não existe consenso para o entendimento e aceitação do contexto informacional como um ambiente de negócio. Além disso, ou justamente por causa dessa situação, o 'negócio da informação' é pouco estudado e compreendido na ciência da informação. Esta realidade dificulta a visualização do significado desse tipo de negócio em sua ampla potencialidade, complexidade e especificidade.

$\mathrm{Na}$ figura 1 podem ser observados, de forma esquemática e em conjunto, os diversos atores sociais do mercado da informação para entender o negócio da informação, no qual se inserem as bibliotecas e

FIGURA 1

Negócio da informação

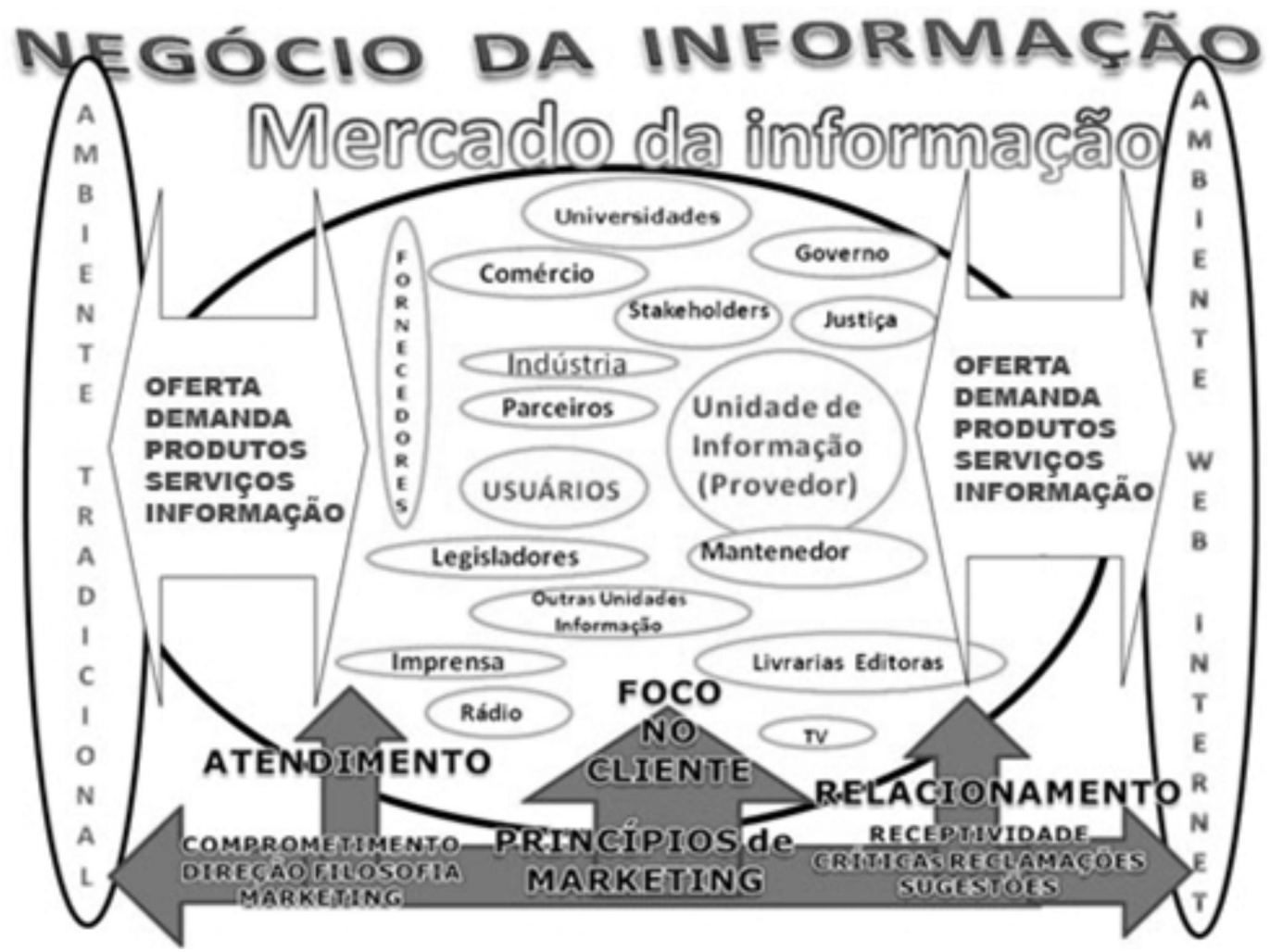

Fonte: Amaral (2008) 
demais unidades afins, como uma das organizações responsáveis pela oferta de produtos e serviços de informação tanto no ambiente tradicional quanto no universo da Web.

É nesse cenário de negócio da informação que se desenvolve o processo de gestão da informação e do conhecimento nas organizações, incluindo entre elas as unidades de informação.

A oferta de informação deve atender satisfatoriamente à demanda informacional, a partir da identificação e do entendimento das exigências dos novos usuários / consumidores diante das mudanças de paradigmas da sociedade?

Será que a gestão da informação e do conhecimento nas unidades de informação é orientada para o mercado e desenvolvida sob a ótica do negócio da informação?

Os profissionais responsáveis pela oferta de informação, em especial os gestores, são capazes de exercer a gestão da informação e do conhecimento nas organizações em que atuam, de modo a satisfazer a demanda informacional por meio de adequada oferta de produtos e serviços de informação? (AMARAL, 2008).

\section{DESEMPENHO DAS UNIDADES DE INFORMAÇÃO E MARKETING DA INFORMAÇÃO}

No desabrochar do século XXI, profissionais e organizações precisam ter acesso às novas tecnologias e aos novos mercados. Indivíduos, grupos de indivíduos, comunidades e organizações devem ir além das fronteiras dos sistemas organizacionais para acessar e compartilhar informações, criando novos conhecimentos.

A evolução das tecnologias de informação e comunicação permite que as unidades de informação, além de atuantes no ambiente tradicional de suas instalações físicas, possam marcar presença na internet por meio dos seus websites. Porém, a corrida para marcar presença na internet contribuiu no sentido que, ao mesmo tempo em que essas organizações aprendiam a criar um website, ele passava a representar a organização na Web. Assim, o desempenho dos websites dessas organizações na oferta de produtos e serviços também está relacionado aos processos de gestão da informação e do conhecimento.

Logo, o gestor da unidade de informação precisa contribuir positivamente para que a sociedade perceba o valor de sua atuação na mediação e no acesso à informação de todo tipo, bem como na catalisação do conhecimento em todas as áreas do saber, em alinhamento com o mercado da informação na área de negócio em que a organização mantenedora da unidade de informação se insere.

Assim, novo e inovador estilo de gestão da informação e do conhecimento se faz necessário diante das exigências a serem cumpridas pelas unidades de informação e de seus profissionais no desempenho dos seus papéis como agentes sociais capazes de enfrentar e transformar a realidade com profissionalismo e competência de modo a contribuir positivamente para a evolução da sociedade.

Apesar de a informação ser considerada o recurso dos mais importantes nas organizações, ela representa uma classe particular dentre os demais recursos. As diferenças decorrem do seu próprio potencial, assim como do desafio de administrála ou gerenciá-la. A informação é infinitamente reutilizável, não se deteriora nem se deprecia, e seu valor é determinado exclusivamente pelo usuário; a fortuna de uns é a desgraça dos outros (MCGEE; PRUSAK, 1994, p. 23).

Portanto, se os profissionais responsáveis pelas unidades de informação não souberem destacar o valor do recurso informação no desempenho da sua função de ajudar as organizações e os indivíduos a construírem um contexto informacional bem- 
sucedido, ao atuarem como agentes sociais colaboradores da evolução da sociedade, seus valores não serão reconhecidos por ela.

A descrição do cenário de negócio do mercado da informação, sob o enfoque econômico das leis da informação formuladas por Moody e Walsh (1999), mostrou que é possível considerar os ajustes entre oferta e demanda desse produto tão peculiar, como é a informação,desde que essas variações sejam gerenciadas por profissionais e organizações comprometidos com as especificidades da oferta e demanda de produtos e serviços informacionais.

Isto reforça a ênfase na importância do usuário como cliente consumidor de informação e a adequação da oferta dos produtos e serviços aos interesses e necessidades do usuário que a busca. Clientes cada vez mais exigentes vão considerar os produtos e serviços de informação oferecidos em função do valor agregado que eles possam lhes oferecer.

Modernamente, as novas tecnologias aplicadas à informação e à comunicação permitem que enormes e variadas quantidades de dados sobre pessoas, tanto físicas quanto jurídicas, sejam armazenadas em bancos de dados de relevantes informações. Essa evolução torna possível agrupar consumidores por dados de similaridade que possibilitam planejar as mais diferentes operações e atividades de marketing. O contato direto com os consumidores, consequentemente, poderá ser realizado por outros canais, independentemente da sua presença física na biblioteca. Passam a existir oportunidades de contato direto um a um, com muitos consumidores e de modo instantâneo.

A principal tarefa da administração de uma organização orientada para marketing, qualquer que seja essa organização, inclusive uma biblioteca ou unidade de informação, é determinar as necessidades e os desejos do seu mercado-alvo para satisfazê-los com adequado design, comunicação e distribuição, além de um preço de oferta competitivamente viável.
Sob outro ângulo, é preciso considerar que o marketing tem suas origens no setor lucrativo, embora, desde 1969, Kotler e Levy (1969) tenham admitido e validado a possibilidade da adoção das técnicas mercadológicas pelas organizações do setor sem fins de lucro. Portanto, trata-se de uma transposição conceitual ainda recente e isso pode justificar o pequeno quantitativo de estudiosos e pesquisadores da área de ciência da informação interessados no marketing da informação.

Cada organização envolvida com os processos de gestão da informação e do conhecimento pode atribuir uma importância diferente e conduzir as atividades de marketing de forma distinta, dependendo de sua filosofia de ação (AMARAL, 2004, p.59-60). A filosofia de atuação da unidade de informação orientada para o mercado volta-se para o atendimento e o relacionamento com a sua clientela, com ênfase na função de troca, mediante ações administrativas, sem perder de vista os objetivos organizacionais.

Existe uma convergência de opinião percebida nas obras de Amaral (1998), Kotler (2000), Godin (2000) e Peppers e Rogers (1996), quando o assunto é a utilização de informações dos clientes para o estabelecimento de relacionamentos eficientes e eficazes entre empresas e consumidores. Não importa com qual nome essa estratégia se apresente: marketing de relacionamento, marketing de segmento, marketing um-a-um ou marketing de permissão. Seja qual for a denominação adotada para o marketing, o levantamento das preferências e a segmentação com vistas à interação personalizada são pontos convergentes na opinião dos autores mencionados. (VIEIRA, 2006, p.176-177).

Além da confusão terminológica, observa-se que os ambientes de informação, depois do surgimento da internet e com a evolução da Web social, enfrentam barreiras para ampliar a oferta de informação com a utilização adequada da potencialidade dos recursos tecnológicos disponíveis. 
Tudo isso vem reforçar a ideia inovadora de que a unidade de informação precisa ser vista como empresa inserida no negócio da informação, pois a informação é a matéria-prima para geração de conhecimento e ambos são ativos intangíveis de relevância estratégica na evolução da sociedade.

Parte-se do princípio que marketing da informação é um processo gerencial capaz de contribuir para garantir o futuro da biblioteca e demais unidades de informação como atividade inovadora e criativa, que envolve o planejamento, execução e controle da concepção, determinação de preço, promoção e distribuição de ideias, produtos e serviços de informação. Essa troca com os usuários não apenas deve satisfazer às suas necessidades atuais, consumidores dos produtos e serviços de informação que são oferecidos. O pensamento recente sobre marketing da informação sugere que a tarefa da biblioteca não seja apenas prover necessidades de informação momentâneas, mas também inovar com a oferta de produtos e serviços de informação capazes de atender os interesses da clientela no futuro.

A ênfase nos princípios do marketing da informação pressupõe: (a) comprometimento com a filosofia de marketing adotada pelos gestores da unidade de informação; (b) suporte administrativo da alta direção da organização mantenedora da unidade de informação; (c) desenvolvimento das atividades da unidade de informação com foco no cliente; (d) preocupação com o atendimento ao público-alvo, receptividade às críticas, reclamações e sugestões; (e) divulgação dos benefícios advindos da adoção das técnicas de marketing; e acima de tudo (f) destaque para o relacionamento entre a unidade de informação e seus públicos.

Marketing da informação pressupõe o interesse em compreender as necessidades, percepções, preferências, os padrões de comportamento para se informar da audiência-alvo, com o intuito de oferecer produtos e serviços de informação que os usuários demandam. Além disso, o compromisso com a oferta exige a preocupação e o interesse pela satisfação do usuário no atendimento, a adequação das mensagens, da mídia, dos custos e das facilidades tecnológicas de comunicação para estabelecer e manter relacionamento em duas vias entre os que demandam (usuários) e os que oferecem informação (unidade prestadora de serviços). Esta forma inovadora de gestão se reverterá em maior visibilidade das atividades desenvolvidas pela unidade de informação na área de negócio do mercado da informação em que sua organização mantenedora se insere. Desse modo, o marketing da informação como abordagem inovadora da gestão da informação e do conhecimento também contribuirá para destacar o valor da atuação das unidades e profissionais da informação no desenvolvimento da sociedade.

\section{CONSIDERAÇÕES FINAIS}

A adoção das técnicas mercadológicas depende, essencialmente, de pesquisa e estudo sobre a adoção do marketing no âmbito da ciência da informação no contexto específico onde será aplicado. Tratase de um profissionalismo caracterizado pela postura de respeito às atividades desenvolvidas, entendendo o verdadeiro papel social, político, educacional, informacional e cultural do profissional da informação, que vai além da preocupação com as regras do processamento técnico, sem menosprezálas. Reconhece a necessidade do tratamento eficiente da coleção, qualquer que seja seu suporte e formato de apresentação, focalizando prioritariamente o usuário, considerado como público-alvo a ser atendido pela unidade de informação, seja ela uma biblioteca ou não, desde que esteja voltada para o negócio e o mercado da informação em que atua.

Bibliotecas e demais unidades de informação devem estar preocupadas em manter um relacionamento em duas vias com os seus públicos, em especial com os seus usuários, considerados clientes e/ou 
consumidores, para conhecer seus perfis de interesse pelos produtos e serviços de informação a serem oferecidos.

O desenvolvimento de estudos e pesquisas sobre marketing da informação na área da ciência da informação poderá contribuir no aprimoramento do desempenho da prestação de serviços de informação direcionada para o atendimento e o relacionamento com os diversos públicos das bibliotecas e demais unidades de informação. Essas organizações devem utilizar todo o potencial da infraestrutura das novas tecnologias da informação e comunicação em prol do reconhecimento do valor agregado da informação e do conhecimento nos seus processos organizacionais.

Desse modo, poderão atuar e contribuir positivamente no contexto do mercado da informação da área de negócio de suas organizações mantenedoras. Isto porque a ótica do marketing da informação busca o melhor desempenho possível ao admitir a velocidade das mudanças que ocorrem no mercado da informação. Mais do que isso, sempre é bom lembrar que o termo marketing quer dizer mercado em movimento.

Assim, amplia-se a capacidade do marketing da informação para dar visibilidade ao papel desempenhado pelas bibliotecas e demais unidades de informação na sociedade como organizações capazes de gerenciar a informação e o conhecimento na área de negócio de seus mantenedores, sejam eles do setor lucrativo ou não.

Artigo submetido em 17/03/2011 e aceito em 12/03/2012.

\section{REFERÊNCIAS}

AMARAL, S.A. do. Gestão da informação e do conhecimento nas organizações e a orientação de marketing. Informação \& Informação, Londrina, v.13, Número Especial, p. 52-70, 2008.

. Marketing: abordagem em unidades de informação. Brasília: Thesaurus, 1998.

Marketing da informação na Internet, ações de promoção. Colaboração de S.P. Santos e W.J.Araújo. Campo Grande: Editora da UNIDERP, 2004. 330p.

BARRETO, A.de A. A eficiência técnica e econômica e a viabilidade de produtos e serviços de informação. Ciência da Informação, v. 25, n. 3, 1996.

O mercado de informação no Brasil. Informação \& Informação, v. 5, n. 1, p. 25-34, jan./jun. 2000.

oferta e a demanda da informação: condições técnicas, econômicas e políticas. Ciência da Informação, v.28, n.2, p. 168-173, mai./ago. 1999.

BELL, D. O Advento da Sociedade Industrial. 1. ed. São Paulo :Cultrix, 1977.

BOTELHO, T. M. ; AMARAL, S. A. ; BAPTISTA, S. G. . Information and society: an inteligent society in transformation? International Journal of Information and Library Research, Londres, v. 6, n. 1/2, p. 64-76, 1994.

CASTELls, M. A sociedade em rede. São Paulo: Paz e Terra, 1999. (A era da informação; economia, sociedade e cultura, v.1)

CUNHA, M.B. da. Construindo futuro: a biblioteca universitária em 2010. Ciência da Informação, Brasília, v.29, p. 71-89, jan./abr.2000.

DERTOUZOS, M. O que será: como o novo mundo da informação transformará nossas vidas? São Paulo: Companhia das Letras, 1997. 413 p.

DE SORDI, J. O. Administração da informação: fundamentos e práticas para uma nova gestão do conhecimento. São Paulo: Saraiva, 2008.

DRUCKER, P. Sociedade pós-capitalista. São Paulo: Pioneira, 1994.

FORRESTER RESEARCH, Inc.. Update, v.7, n.7-8, July/Aug. 2008.

GODFREY, J.et al. Financial Accounting Theory, $3^{\text {rd }}$ ed. New York: John Wiley and Sons, 1997.

GODIN, Seth. Delete o manual. Exame. São Paulo, v.34, n.5, p. 144-148, mar. 2000.

GUINCHAT, C.; MENOU, M. Introdução geral às ciências e técnicas da informação e documentação. 2. ed, corr. aum. Tradução de Miriam Vieira da Cunha. Brasília: IBICT, 1994. 540 p.

HENDERSON, S.; PEIRSON, G. Issues in Financial Accounting, $6^{\text {th }} \mathrm{ed}$. Melbourne, Australia: Longman Cheshire, 1998.

KOTLER, Philip. Administração de marketing. São Paulo: Prentice Hall, 2000. 764p.

Atlas, 1978. 
KOTLER, P., LEVY, S.J. Broadening the concept of marketing. Journal of Marketing, v.33, n.1, Jan. 1969, p. 10-15.

LYOTARD, J. F. O pós-moderno. Rio de Janeiro: J.Olympio, 1990.

MC GEE, J. V.; PRUSAK, L. Gestão estratégica da informação. Rio de Janeiro: Campus, 1994.

MATTELART, A. História da sociedade da informação. São Paulo: Loyola, 2002.

MOODY, D.; WALSH, P. Measuring the value of information: an asset evaluation approach. European Conference on Information Systems, 1999. Disponível: http://wwwinfo.deis.unical. it/ zumpano/2004-2005/PSI/lezione2/ValueOfInformation.pdf. Acesso: 6 de maio de 2009.

MOSTAFA, S.P.; PACHECO, M. O mercado emergente de informação. Ciência da Informação, v. 24, n. 2, 1995.

PEPPERS, D.; ROGERS, M. Marketing um a um: marketing individualizado na era do cliente. Rio de Janeiro: Campus, 1996.
ROBREDO, J. Da Ciência da Informação revisitada aos sistemas humanos de informação. Brasília: Thesaurus; SSRR Informações, 2003. 245p.

ROWLEY, J. Information marketing. $2^{\text {nd }}$ ed. Hants; Burlington: Ashgate Publishing Limited, 2006.

Information marketing in a digital word. Library HiTech, v.20, n.3, p.352-358, 2002.

SAMPAIO, L. A.C. Mapeamento das competências gerenciais necessárias aos gerentes das unidades de informação dos Tribunais Superiores do Poder Judiciário Brasileiro. Brasília: Universidade de Brasília. Faculdade de Ciência da Informação. Dissertação de Mestrado. 2009.

VALENTIM, M.P. O mercado de informação brasileiro. Informação \& Informação, v.5, n.1, p. 35-42, jan./jun. 2000.

VIEIRA, F.J.T. Personalização de informações em portais corporativos: o caso Serpro. In: CARVALHO, I.; MENDES, S.P.; VERAS, V.M., org. Gestão do conhecimento; uma estratégia empresarial. Brasília: J. J. Gráfica e Comunicação Ltda., 2006. Cap.7, p.172-194.

WURMAN, R.S. Ansiedade de informação: como transformar informação em compreensão. São Paulo: Cultura, 1995. 